\title{
Patient Willingness to Have Tests to Guide Antibiotic Use for Respiratory Tract Infections: From the WWAMI Region Practice and Research Network (WPRN)
}

\author{
Malaika Schwartz, MPH, Victoria Hardy, MSc, Gina A. Keppel, MPH, \\ William Alto, MD, Jaime Hornecker, PharmD, Beth Robitaille, MD, Jon Neher, MD, \\ John Holmes, PharmD, M. Ashworth Dirac, MD, PhD, Allison M. Cole, MD, MPH, and \\ Matthew Thompson, MBChB, MPH, DPhil
}

Introduction: The majority of consultations for acute respiratory tract infections (RTIs) lead to prescriptions for antibiotics, which have limited clinical benefit. We explored patients' willingness to have blood tests as part of the diagnostic work-up for RTIs, and patient knowledge about antibiotics.

Methods: Patients at 6 family medicine clinics were surveyed. Regression modeling was used to determine independent predictors of willingness to have venous and point-of-care (POC) blood tests, and knowledge of the value of antibiotics for RTIs.

Results: Data were collected from 737 respondents (response rate $83.8 \%$ ), of whom $65.7 \%$ were women, $\mathbf{6 0 . 1 \%}$ were white, and $25.1 \%$ were current smokers; patients' mean age was 46.9 years. Sex (female), race (white), and a preference to avoid antibiotics were independent predictors of greater level of antibiotic knowledge. A total of $63.1 \%$ were willing to have a venous draw and $79 \%$ a POC blood test, to help guide antibiotic decision-making. Non-American Indian/Alaskan Native race, current smoking, and greater knowledge of antibiotics were independent predictors of willingness to have a POC test.

Conclusion: A large majority of patients seemed willing to have POC tests to facilitate antibiotic prescribing decisions for RTIs. Poor knowledge about antibiotics suggests better education regarding antibiotic use might influence patient attitudes towards use of antibiotics for RTIs. (J Am Board Fam Med 2017;30:645-656.)

Keywords: Antibacterial Agents, Decision Making, Family Physicians, Hematologic Tests, Patient Preference, Prescriptions, Point-of-Care Systems, Practice-based Research, Referral and Consultation, Respiratory Tract Infections

Acute respiratory tract infections (RTIs) are among the most common reasons adults and children present to family medicine clinics. ${ }^{1,2}$ Patients' consul-

\footnotetext{
This article was externally peer reviewed.

Submitted 28 February 2017; revised 1 May 2017; accepted 2 May 2017.

From the Department of Family Medicine, University of Washington, Seattle (MS, VH, GAK, AMC, MT); the Seattle Indian Health Board, Seattle, WA (WA); the University of Wyoming Family Medicine Residency, Casper (JH, BR); Valley Family Medicine, Renton (JN); the Department of Family Medicine, Idaho State University, Pocatello (JH); the Swedish First Hill Family Medicine Residency Clinic, Seattle (MAD); the Harborview Medical Center, Seattle (AMC); and the Institute of Translational Health Sciences, Seattle (AMC).

Funding: This project was funded by an unrestricted grant from Alere. The WPRN is supported by the National Center for Advancing Translational Sciences (NCATS) of the
}

tation decisions are driven by a variety of factors during RTI episodes, including perceived severity of illness, desire for symptomatic relief, and concerns about complications. ${ }^{3-5}$ Despite evidence that

National Institutes of Health (NIH) under award UL1TR000423.

Conflict of interest: MT has received funding from the National Science Foundation to develop point-of-care tests for group A streptococcus and chlamydia trachomatis, and has acted as a consultant to Roche Molecular Diagnostics. No other conflicts of interest have been reported.

Disclaimer: The content is solely the responsibility of the authors and does not necessarily represent the official views of the funders of this study nor of the National Institutes of Health.

Corresponding author: Matthew Thompson, MBChB, MPH, DPhil, Department of Family Medicine, University of Washington, Seattle, WA 98195 (E-mail: mjt@uw.edu). 
antibiotics confer little benefit for most RTIs, the majority of patients presenting with RTIs are inappropriately prescribed broad-spectrum antibiotics. ${ }^{6-9}$ Diagnostic uncertainty, patient demand, and perceived patient expectations for antibiotics have been identified as key factors that influence antibiotic prescribing decisions. ${ }^{4,10,11}$

A variety of strategies have been introduced in attempts to safely reduce antibiotic prescribing. Some have been directed toward patients in order to change their knowledge and beliefs about antibiotics, such as education campaigns from the Centers for Disease Control and Prevention, whereas other initiatives have been directed toward clinicians, such as delayed prescribing, clinical prediction rules to help identify patients at risk of complications, and point-of-care (POC) diagnostic tests to enhance diagnostic certainty. ${ }^{12-14}$ Despite some success with these strategies, lack of confidence differentiating bacterial infections that may benefit from antibiotics from self-limiting viral RTIs remains an impediment to further reductions in antibiotic prescribing by clinicians. ${ }^{10,11}$

The recently announced National Action Plan for Combating Antibiotic-Resistant Bacteria has highlighted the need for more POC testing to guide treatment decisions. ${ }^{15}$ Two main types of POC tests are available in primary care settings to improve diagnostic certainty for RTIs: tests that detect individual pathogens (eg, influenza, group A streptococcus) and tests that quantify the response to infection, such as C-reactive protein (CRP), which is an acute-phase protein synthesized by the liver more quickly during bacterial than viral infections, thus facilitating differentiation of bacterial from viral RTI etiologies. ${ }^{16}$ Strong evidence shows that POC CRP tests provide physicians with added diagnostic information that can facilitate improved targeting of antibiotics. ${ }^{17-19}$ Indeed, a systematic review of 13 trials of POC CRP testing in $>10,000$ adults with suspected RTIs in primary care found a $25 \%$ reduction in antibiotic prescribing, with no increase in adverse events, reconsultations, or worsening of patient experience. ${ }^{20}$ Changes to the culture of antibiotic prescribing and potential introduction of new diagnostic tests requires an understanding of patients' knowledge, views, and attitudes. ${ }^{21,22}$ While primary care physicians have highlighted a need for improved diagnostic tools to help them guide antibiotic prescribing decisions, no recent attempts have been made to determine patients' willingness to avoid antibiotics for RTIs or their perceptions of these tests in the United States. ${ }^{23,24}$ The aim of this study, therefore, was to explore patients' knowledge and preferences regarding antibiotics for RTIs and their willingness to have a blood test in order to help guide antibiotic use for RTIs.

\section{Methods}

\section{Sampling and Recruitment}

Six primary care clinics from the WWAMI Region Practice and Research Network (WPRN), a practicebased research network in the region comprising the 5 states of Washington, Wyoming, Alaska, Montana, and Idaho, participated in this study. The WPRN Coordinating Center at the University of Washington facilitated identification of interested clinics. Participating clinics were located in Washington, Wyoming, and Idaho and included both locations serving rural areas and those serving large metropolitan areas; 2 sites were federally qualified health centers and 3 were hospital-associated clinics.

Adult patients ( $\geq 18$ years old) presenting for any reason for a visit to a participating clinic during a 5-day period in November/December 2015 were consecutively enrolled and invited by clinic staff to complete an anonymous survey upon arrival for their office visit. The survey was available in English and Spanish. Completed surveys were deposited into a designated box in the clinic reception area. Front desk staff tracked how many surveys were handed out in order to calculate response rates, and the collection boxes were mailed to the WPRN Coordinating Center at the end of the week. The University of Washington Human Subjects Review Board approved this study.

\section{Survey Instrument}

The survey included questions about patient demographics (eg, age, gender, ethnicity, race), overall health status, type of health insurance, smoking status, number of office visits for an RTI within the previous 12 months, number of antibiotic prescriptions for an RTI issued to the patient in the previous 12 months, patient preference for antibiotic treatment for RTI, and willingness to have a POC fingerstick test and venous draw (assessed using a 5 -point Likert scale). Patients were asked to indicate the 3 most important reasons that would help them decide to have a POC fingerstick test. The survey also asked patients about the types of respi- 
ratory conditions which they believed would be improved by antibiotics (ie, those caused by viruses, bacteria, or viruses and bacteria), which was used as a measure of patients' knowledge of antibiotics. ${ }^{25}$ Respondents were asked to select a single response for all items except race, type of health insurance, and the 3 most important reasons for deciding to have a POC fingerstick test. (See the Appendix for the survey instrument.)

\section{Data Management}

Survey responses were double-entered into a Research Electronic Data Capture database. ${ }^{26}$ Data sets were cross-referenced to identify discrepancies using the of command in StataIC 14 (StataCorp LLC, College Station, TX) and were resolved by manually reviewing the relevant surveys. Age was categorized into 3 groups: $<40,40$ to 59 , and $\geq 60$ years. Given the small number of respondents identifying as Asian and Pacific Islanders, these were combined. Those who selected $>1$ race option were assigned to a "multiple race" category. Respondents who selected multiple options for health status were assigned to the better health status (eg, if they selected both "good" and "moderate," their health was categorized as "good"). A "multiple/ other type of insurance" category was created for respondents who selected multiple types of health insurance, "other" health insurance, or who did not know their insurance type; however, those who selected both Medicare and Medicaid were combined into 1 category. Subjects who selected "private insurance" and another type of health insurance were assigned to a private insurance category, as secondary insurance is often supplementary. Respondents who selected multiple options to the question about antibiotic knowledge were assigned to a "do not know" category. Patients selecting multiple options regarding their willingness to have blood drawn from their arm or willingness to have a POC fingerstick test were assigned the category closer to neutral (eg, if they selected both "very unwilling" and "somewhat unwilling," they were assigned to the "somewhat unwilling" category). Responses were then transformed into a binary variable of "somewhat willing or very willing" and "neutral, somewhat unwilling, or very unwilling."

\section{Data Analysis}

Survey response rates were estimated by counting the numbers of surveys issued at each site and the number of nonblank surveys returned. Descriptive statistics were used to describe respondents' characteristics (age, gender, ethnicity, race, insurance status, smoking status, and overall health status) and antibiotic prescriptions used by them in the previous 12 months, preferences for antibiotics, knowledge of antibiotics, willingness to have blood drawn from the arm, willingness to have a fingerstick blood test, and the most important reasons for deciding to have a POC fingerstick test.

We explored associations between potential predictor variables (eg, patient demographics, number of prior visits for an RTI) and the outcome of knowledge of antibiotics using the Pearson $\chi^{2}$ test. We used the same methods to predict the outcome of willingness to have a POC fingerstick test, using knowledge of antibiotics as an additional predictor variable. Backward stepwise logistic modeling was used to identify significant predictors of knowledge of antibiotics and of willingness to have a POC fingerstick test. Demographic characteristics, doctor visits for an RTI, preferences for antibiotics, knowledge of antibiotics, and willingness to have blood drawn from the arm were considered independent predictor variables, and dummy variables were created for categorical variables such as health status or race. Several regression models were used to explore determinants of knowledge of antibiotics and willingness to have a POC fingerstick test. The final adjusted models include predictor variables that were identified after examining the strength and significance of the association between predictor variables and outcomes.

\section{Results}

A total of 743 patients returned completed surveys, of which 6 were excluded because they were filled out on behalf of children. The final sample comprised 737 surveys, with an overall response rate of $83.8 \%$ (range, $64.7-99.0 \%$ ). A total of 707 patients (95.7\%) completed the survey in English.

\section{Respondent Characteristics}

Respondents had a mean age of 46.9 years (range, $18-93$ years), and most (65.7\%) were female. The most frequent race and ethnicities selected were white (60.1\%), Hispanic/Latino (14.0\%), and black or African American (10.7\%) (Table 1). Among respondents, $74 \%$ considered their health to be moderate, 
Table 1. Characteristics of Respondents

\begin{tabular}{lc}
\hline Age $($ years $)(\mathrm{n}=722)$, mean $\pm \mathrm{SD}$ & $46.9 \pm 17.1$ \\
$<40$ & $283(39.2)$ \\
$40-59$ & $260(36.0)$ \\
$\geq 60$ & $179(24.8)$ \\
Gender $(\mathrm{n}=718)^{*}$ & \\
Male & $246(34.3)$ \\
Female & $472(65.7)$ \\
Ethnicity (n $=672)$ & \\
Non-Hispanic/Latino & $578(86.0)$ \\
Hispanic/Latino & $94(14.0)$ \\
Race (n $=697)^{\dagger}$ & \\
White only & $419(60.1)$ \\
Black only & $82(11.8)$ \\
American Indian/Alaska Native only & $54(7.7)$ \\
Asian/Pacific Islander only & $60(8.6)$ \\
Multiple/other race & $82(11.8)$ \\
Health status (n $=721)$ & \\
Poor & $187(25.9)$ \\
Average & $164(22.8)$ \\
Good & $370(51.3)$ \\
Smoking status (n $=726)$ & \\
Never smoker & $32(4.3)$ \\
Former smoker & $183(25.3)$ \\
Current smoker & $365(50.5)$ \\
Health insurance (n $=723)^{\ddagger}$ & $100(23.8)$ \\
No health insurance & \\
Private health insurance only & \\
Medicaid and/or Medicare only & \\
Multiple/other health insurance & \\
Survey language $(\mathrm{n}=737)$ & \\
English & \\
Spanish & \\
\hline
\end{tabular}

Data are $\mathrm{n}(\%)$ unless otherwise indicated.

*One respondent wrote "FTM" (female to male), so they were categorized as male.

${ }^{\dagger}$ Because respondents were allowed to select more than 1 race/ ethnicity, we counted 747 responses for 697 subjects.

${ }^{\ddagger}$ Because respondents were allowed to select more than 1 type of insurance, we counted 852 responses for 723 subjects.

good, or excellent. Approximately half (51.9\%) reported they were nonsmokers, whereas $25.1 \%$ were current smokers. Fifty percent reported having Medicare and/or Medicaid insurance, $25.3 \%$ had only private health insurance, and $10.4 \%$ had no health insurance. The majority of respondents (66.1\%) indicated they had no doctor visits for RTI in the previous 12 months; $14.6 \%$ had 1 visit and $19.3 \%$ had $\geq 2$ visits (Table 2). A total of $36 \%$ reported they had not been prescribed antibiotics for an RTI in the past 12 months, 35.5\% indicated they had been given antibiotics once, and $28.5 \%$, twice or more.
Table 2. Experience with Respiratory Tract Infections, Preference for and Knowledge about Antibiotics, and Willingness to Have Blood Tests

\begin{tabular}{|c|c|}
\hline \multicolumn{2}{|l|}{$\begin{array}{l}\text { No. of doctor visits for a cough/cold in past } 12 \\
\text { months }(\mathrm{n}=706)\end{array}$} \\
\hline 0 & $467(66.1)$ \\
\hline 1 & $103(14.6)$ \\
\hline$\geq 2$ & $136(19.3)$ \\
\hline \multicolumn{2}{|l|}{$\begin{array}{l}\text { No. of times antibiotics were given for cough/cold } \\
\text { during doctor visit }(n=231)\end{array}$} \\
\hline 0 & $87(36.0)$ \\
\hline 1 & $86(35.5)$ \\
\hline$\geq 2$ & $69(28.5)$ \\
\hline \multicolumn{2}{|l|}{ Preferences for antibiotics $(n=692)$} \\
\hline $\begin{array}{l}\text { I prefer to take antibiotics for a cough or cold, } \\
\text { even if my doctor thinks antibiotics may not } \\
\text { help me. }\end{array}$ & $88(12.7)$ \\
\hline $\begin{array}{l}\text { I prefer to avoid taking antibiotics, but I will } \\
\text { take antibiotics if my doctor thinks they will } \\
\text { help my cough or cold. }\end{array}$ & $604(87.3)$ \\
\hline \multicolumn{2}{|l|}{ Knowledge of antibiotics $(\mathrm{n}=708)^{*}$} \\
\hline Viruses & $68(9.6)$ \\
\hline Bacteria $^{\dagger}$ & $268(37.9)$ \\
\hline Viruses and bacteria & $178(25.1)$ \\
\hline Don't know & $194(27.4)$ \\
\hline \multicolumn{2}{|l|}{ Willingness to undergo arm blood draw $(\mathrm{n}=700)$} \\
\hline Unwilling & $153(21.9)$ \\
\hline Neutral & $105(15.0)$ \\
\hline Willing & $442(63.1)$ \\
\hline \multicolumn{2}{|l|}{ Willingness to undergo fingerstick test $(\mathrm{n}=677)^{\ddagger}$} \\
\hline Unwilling & $102(15.1)$ \\
\hline Neutral & $40(5.9)$ \\
\hline Willing & $535(79.0)$ \\
\hline
\end{tabular}

Data are $\mathrm{n}(\%)$.

*Antibiotic knowledge was measured by a subject's response to the question, "I understand that antibiotics are best for treating coughs and colds that are caused by (viruses, bacteria, viruses/ bacteria, don't know)."

${ }^{\dagger}$ Correct answer.

${ }^{\ddagger}$ Responses from 60 subjects who did not answer the question about willingness to have a fingerstick test are included in the overall results but not in the analyses of associations with this outcome.

\section{Preference for and Knowledge of Antibiotics for Treating RTIs}

The majority of respondents (87.3\%) stated they preferred to avoid taking antibiotics unless their doctor believed the drugs would help their cough or cold. Responses to the question relating to patient knowledge about the etiology of RTIs for which antibiotics may be effective showed that only $37.9 \%$ understood that antibiotics offer most benefit for bacterial infections, whereas $9.6 \%$ believed antibiotics to be effective for viral infections, $25.1 \%$ 
selected the option viral and bacterial infections, and $27.4 \%$ did not know (Table 2).

Respondents who correctly agreed with the statement, "I understand that antibiotics are best for treating coughs and colds that are caused by bacteria," were more likely to be younger, white, female, and non-Hispanic and to prefer to avoid taking antibiotics (Table 3). Regression modeling showed that age group, race, ethnicity, preference for antibiotics, and type of health insurance were independent predictors of knowledge of antibiotics (Table 4). White respondents were significantly more likely to have correct knowledge of antibiotics than those of any other race, and women were 2 times more likely than men to have correct knowledge of antibiotics. In addition, those who preferred not to take antibiotics were 3 times more likely to have correct knowledge of antibiotics than those who preferred to take antibiotics.

\section{Willingness to Have Blood Tests to Guide Antibiotic Use for RTIs}

Nearly two thirds $(63.1 \%)$ of respondents were somewhat or very willing to have blood drawn from their arm, and $79.0 \%$ were somewhat or very willing to have a POC fingerstick test to determine whether they needed to take antibiotics for an RTI (Table 2).

A total of 664 respondents gave 1757 reasons why they would be willing to have a fingerstick test (respondents were allowed to select up to 3 reasons). The 3 most frequently cited reasons were if their doctor recommended the test $(68.8 \%$ of responses), speed of the results $(53.8 \%)$, and if it helped the doctor decide whether antibiotics were needed (41.3\%) (Figure 1).

Willingness to have a fingerstick test to help guide antibiotic use was significantly associated with respondents who were white, considered themselves to be in good health, and were covered by private health insurance. Willingness was also significantly associated with correct knowledge of antibiotics, preference to avoid antibiotics, and willingness to have blood drawn from their arm (Table 3). By contrast, respondents who were unwilling or neutral about having a fingerstick test were more likely to identify as American Indian/ Alaskan Native, to have multiple/other health insurance, and to not have visited their doctor for a cough or cold in the past year.
Regression modeling (Table 4) showed that race, smoking status (current smoker), knowledge of antibiotics (higher level of knowledge), and willingness to have blood drawn from the arm were independent predictors of willingness to have a fingerstick test. Those who identified as American Indian/Alaskan Native only were significantly less willing to have a fingerstick test than those who identified as white only.

\section{Discussion}

\section{Key Findings}

Our results provide new information about patients' preferences and knowledge about antibiotics and their willingness to consider having blood tests to support antibiotic prescribing decisions for RTIs. Nearly 9 of 10 patients $(87.3 \%)$ in family medicine clinics stated they preferred to avoid taking antibiotics for RTIs, yet two thirds (64\%) of those who had visited a doctor for an RTI in the past year had received antibiotics. Patient knowledge about the value of antibiotics for RTIs was somewhat limited: two-thirds did not understand that antibiotics are most effective against bacterial etiologies.

While $63.1 \%$ of patients were willing to have a venous blood draw, a significantly higher proportion (79.0\%) were willing to have a POC fingerstick test to help guide antibiotic use, suggesting that these types of tests may be acceptable to patients. Patients indicated recommendation by a doctor, speed of results, and the ability of the test to help doctors' decision making were key factors guiding their potential willingness to have such tests. Our results also suggest important disparities related to gender, race, ethnicity, and age in terms of both knowledge about antibiotics for RTIs and willingness to consider blood tests for this condition, which may reflect underlying levels of education, access to care, and prior health care experiences.

\section{Strengths and Limitations}

This survey provides new information on patients' knowledge of antibiotics and preferences for treatment for RTIs, and to our knowledge it is the first survey to also provide information about US patients' willingness to consider blood tests in order to inform physicians' decisions regarding prescribing antibiotics for RTIs. Our sample was obtained from several different clinics, shows a very high response rate, and represents several ethnic and racial 
Table 3. Associations between Demographics, Health Status and Attitudes, and Willingness to Have Fingerstick Blood Test and Antibiotic Knowledge

\begin{tabular}{|c|c|c|c|c|}
\hline & \multicolumn{2}{|c|}{ Antibiotic Knowledge } & \multicolumn{2}{|c|}{$\begin{array}{c}\text { Willingness to Have Fingerstick } \\
\text { Blood Test }\end{array}$} \\
\hline & $\begin{array}{l}\text { Incorrect } \\
(\mathrm{n}=440)\end{array}$ & $\begin{array}{l}\text { Correct } \\
(\mathrm{n}=268)\end{array}$ & $\begin{array}{l}\text { Unwilling/Neutral } \\
\quad(\mathrm{n}=142)\end{array}$ & $\begin{array}{l}\text { Willing } \\
(\mathrm{n}=535)\end{array}$ \\
\hline \multicolumn{5}{|l|}{ Age, years $(\mathrm{n}=702)^{*}$} \\
\hline Mean $\pm \mathrm{SD}$ & $47.5 \pm 17.0$ & $45.6 \pm 17.1$ & $45.5 \pm 18.0$ & $47.2 \pm 16.8$ \\
\hline$<40$ & $154(35.5)$ & $123(45.9)$ & $58(42.0)$ & $206(39.0)$ \\
\hline $40-59$ & $169(38.9)$ & $85(31.7)$ & $46(33.3)$ & $193(36.6)$ \\
\hline$\geq 60$ & $111(25.6)$ & $60(22.4)$ & $34(24.6)$ & $129(24.4)$ \\
\hline \multicolumn{5}{|l|}{ Gender $(\mathrm{n}=698)^{*}$} \\
\hline Male & $174(40.3)$ & $64(24.1)$ & $52(38.0)$ & $178(33.8)$ \\
\hline Female & $258(59.7)$ & $202(75.9)$ & $85(62.0)$ & $348(66.2)$ \\
\hline \multicolumn{5}{|l|}{ Ethnicity $(\mathrm{n}=654)^{*}$} \\
\hline Hispanic/Latino & $73(18.3)$ & $17(6.6)$ & $18(14.3)$ & $64(12.9)$ \\
\hline Non-Hispanic/Latino & $325(81.7)$ & $239(93.4)$ & $108(85.7)$ & $434(87.1)$ \\
\hline \multicolumn{5}{|l|}{ Race $(\mathrm{n}=679)^{\star \dagger}$} \\
\hline White only & $211(50.7)$ & $199(75.7)$ & $75(56.0)$ & $322(62.9)$ \\
\hline Black only & $62(14.9)$ & $17(6.4)$ & $15(11.2)$ & $55(10.7)$ \\
\hline American Indian/Alaska Native only & $38(9.1)$ & $14(5.3)$ & $19(14.2)$ & $32(6.3)$ \\
\hline Asian/Pacific Islander only & $45(10.8)$ & $12(4.6)$ & $11(8.2)$ & $42(8.2)$ \\
\hline Multiple/other race & $60(14.4)$ & $21(8.0)$ & $14(10.4)$ & $61(11.9)$ \\
\hline \multicolumn{5}{|l|}{ Health insurance $(\mathrm{n}=703)^{* \dagger}$} \\
\hline No health insurance & $42(9.6)$ & $31(11.6)$ & $13(9.2)$ & $56(10.7)$ \\
\hline Private health insurance only & $83(19.0)$ & $98(36.7)$ & $25(17.7)$ & $148(28.1)$ \\
\hline Medicaid and/or Medicare only & $235(53.9)$ & $119(44.6)$ & $74(52.5)$ & $262(49.8)$ \\
\hline Multiple/other health insurance & $76(17.4)$ & $19(7.1)$ & $29(20.6)$ & $60(11.4)$ \\
\hline \multicolumn{5}{|l|}{ Health status $(\mathrm{n}=702)$} \\
\hline Poor & $118(27.2)$ & $65(24.2)$ & $28(20.1)$ & $140(26.5)$ \\
\hline Average & $104(24.0)$ & $56(20.9)$ & $37(26.6)$ & $119(22.5)$ \\
\hline Good & $212(48.8)$ & $147(54.9)$ & $74(53.2)$ & $269(60.0)$ \\
\hline \multicolumn{5}{|l|}{ Language $(\mathrm{n}=708)^{*}$} \\
\hline Spanish & $30(6.8)$ & $1(0.4)$ & $3(2.1)$ & $22(4.1)$ \\
\hline English & $410(93.2)$ & $267(99.6)$ & $139(97.9)$ & $513(95.9)$ \\
\hline \multicolumn{5}{|l|}{ Smoking status $(\mathrm{n}=706)$} \\
\hline Never smoker & $228(52.0)$ & $137(51.3)$ & $73(51.8)$ & $273(51.7)$ \\
\hline Former smoker & $97(22.0)$ & $65(24.3)$ & $35(24.8)$ & $120(22.7)$ \\
\hline Current smoker & $114(26.0)$ & $65(24.3)$ & $33(23.4)$ & $135(25.6)$ \\
\hline \multicolumn{5}{|c|}{$\begin{array}{l}\text { No. of doctor visits for a cough/cold in past } 12 \\
\text { months }(\mathrm{n}=688)\end{array}$} \\
\hline 0 & $285(67.2)$ & $170(64.4)$ & $94(70.7)$ & $337(65.2)$ \\
\hline 1 & $55(13.0)$ & $45(17.0)$ & $18(13.5)$ & $79(15.3)$ \\
\hline$\geq 2$ & $84(19.8)$ & $49(18.6)$ & $21(15.8)$ & $101(19.5)$ \\
\hline \multicolumn{5}{|c|}{$\begin{array}{l}\text { No. of times antibiotics given for cough/cold } \\
\text { during doctor visit }(\mathrm{n}=226)\end{array}$} \\
\hline 0 & $43(32.3)$ & $38(40.9)$ & $12(30.8)$ & $64(36.6)$ \\
\hline 1 & $45(33.8)$ & $36(38.7)$ & $16(41.0)$ & $63(36.0)$ \\
\hline$\geq 2$ & $45(33.8)$ & $19(20.4)$ & $11(28.2)$ & $48(27.4)$ \\
\hline \multicolumn{5}{|l|}{ Preferences for antibiotics $(\mathrm{n}=686)^{*}$} \\
\hline Prefer to take antibiotics & $70(16.6)$ & $17(6.4)$ & $21(15.6)$ & $60(11.6)$ \\
\hline Prefer to avoid taking antibiotics & $352(83.4)$ & $247(93.6)$ & $114(84.4)$ & $456(88.4)$ \\
\hline
\end{tabular}

Contined 


\begin{tabular}{|c|c|c|c|c|}
\hline & \multicolumn{2}{|c|}{ Antibiotic Knowledge } & \multicolumn{2}{|c|}{$\begin{array}{c}\text { Willingness to Have Fingerstick } \\
\text { Blood Test }\end{array}$} \\
\hline & $\begin{array}{l}\text { Incorrect } \\
(\mathrm{n}=440)\end{array}$ & $\begin{array}{l}\text { Correct } \\
(\mathrm{n}=268)\end{array}$ & $\begin{array}{l}\text { Unwilling/Neutral } \\
\qquad(\mathrm{n}=142)\end{array}$ & $\begin{array}{l}\text { Willing } \\
(\mathrm{n}=535)\end{array}$ \\
\hline \multicolumn{5}{|c|}{ Knowledge of antibiotics $(\mathrm{n}=661)^{\dagger}$} \\
\hline Incorrect & N/A & N/A & $99(71.7)$ & $307(58.7)$ \\
\hline Correct & - & - & $39(28.3)$ & $216(41.3)$ \\
\hline \multicolumn{5}{|c|}{ Willingness to undergo arm blood draw $(\mathrm{n}=662)^{\dagger}$} \\
\hline Unwilling & $101(23.8)$ & $49(18.4)$ & $87(62.6)$ & $53(10.1)$ \\
\hline Neutral & $58(13.6)$ & $47(17.7)$ & $45(32.4)$ & $54(10.3)$ \\
\hline Willing & $266(62.6)$ & $170(63.9)$ & $7(5.0)$ & $416(79.5)$ \\
\hline \multicolumn{5}{|c|}{ Willingness to undergo fingerstick test $(\mathrm{n}=661)^{*}$} \\
\hline Unwilling & $75(18.5)$ & $25(9.8)$ & N/A & N/A \\
\hline Neutral & $24(5.9)$ & $14(5.5)$ & - & - \\
\hline Willing & 307 (75.6) & $216(84.7)$ & - & - \\
\hline
\end{tabular}

Data are $\mathrm{n}(\%)$ unless otherwise indicated.

${ }^{\dagger}$ Significant at the 0.05 level for willingness to have fingerstick blood test.

*Significant at the 0.05 level for antibiotic knowledge.

N/A, not applicable.

groups. The favorable responses toward blood tests suggests that introducing POC tests such as CRP into family medicine might be acceptable to patients. Our findings highlight persisting gaps in patient understanding regarding appropriate antibiotic use, despite antibiotic stewardship campaigns such as Get Smart About Antibiotics, targeted toward public education. Yet, paradoxically, the majority of patients in our sample wanted to avoid antibiotics for RTIs, implying that the overarching message of these campaigns may be permeating, but the underpinning rationale may need to be reframed in order to be better understood, and may need to be made more widely accessible.

Our study has several potential limitations. First, while we believe our sampling strategy included a representative sample of patients attending family medicine clinics in the United States, we acknowledge that the practices selected (most of which are family medicine residency training sites) are not typical of all primary care settings in the United States where patients present with RTIs (eg, urgent care and pharmacy-based clinics). Second, a preference to avoid antibiotics for RTIs could have been confounded by the fact that most of our sample had not presented for an RTI in the previous 12 months. Furthermore, we did not capture patients' reasons for presenting to the clinic at the time of the survey. Patients who have RTIs only infrequently and those presenting for a non-RTI-re- lated medical reason may respond differently to those who are symptomatic with regard to willingness to have tests and treatment preferences. Third, because we did not collect the demographic characteristics of those patients who declined to complete/submit a survey, we are unable to determine how similar our respondents are to the total population registered with the participating clinics, and indeed against the broader US population. Finally, we did not ask patients to indicate their prior experiences with POC fingerstick tests or venous blood draws, which may influence their willingness to have these blood tests.

\section{Comparison with the Existing Literature}

Most patients who completed our survey did not adequately understand when antibiotics are indicated for RTIs, findings that are similar to those of studies of public knowledge captured a decade ago. ${ }^{25}$ The apparent desire of patients to avoid antibiotics seems contrary to studies of primary care clinicians' perceptions of continued high levels of patient demand as a major driver of inappropriate prescribing of antibiotics for RTIs. ${ }^{27}$ The diagnostic uncertainty that clinicians face in primary care when caring for patients with acute cough also suggests an appetite for additional diagnostic tools to help improve decision making. ${ }^{10}$ Our findings suggest that patients too would be keen on additional such testing. ${ }^{10}$ This echoes a multicountry 
Table 4. Crude and Adjusted Odds Ratios of Willingness to Have a Fingerstick Test and Antibiotic Knowledge

\begin{tabular}{|c|c|c|c|c|}
\hline & \multicolumn{2}{|c|}{ Antibiotic Knowledge } & \multicolumn{2}{|c|}{ Willingness to Have a Fingerstick Test } \\
\hline & Crude $(\mathrm{n}=708)$ & Adjusted $^{*}(\mathrm{n}=632)$ & Crude $(\mathrm{n}=677)$ & Adjusted $^{\dagger}(\mathrm{n}=652)$ \\
\hline \multicolumn{5}{|l|}{ Age (years) } \\
\hline$<40$ & Reference & Reference & Reference & Reference \\
\hline $40-59$ & $0.63(0.44-0.90)^{\ddagger}$ & $0.70(0.47-1.05)$ & $1.18(0.77-1.82)$ & $1.15(0.63-2.10)$ \\
\hline$\geq 60$ & $0.68(0.46-1.00)$ & $0.59(0.37-0.94)^{\ddagger}$ & $1.07(0.66-1.72)$ & $1.65(0.82-3.30)$ \\
\hline \multicolumn{5}{|l|}{ Sex } \\
\hline Male & Reference & Reference & Reference & Reference \\
\hline Female & $2.13(1.51-2.99)^{\S}$ & $2.20(1.50-3.22)^{\S}$ & $1.20(0.81-1.77)$ & $0.86(0.50-1.50)$ \\
\hline Hispanic/Latino & Reference & Reference & Reference & Reference \\
\hline Non-Hispanic/Latino & $1.33(0.83-2.16)$ & $0.49(0.27-0.91)^{\ddagger}$ & $0.89(0.50-1.56)$ & $0.99(0.45-2.20)$ \\
\hline \multicolumn{5}{|l|}{ Race } \\
\hline White only & Reference & Reference & Reference & Reference \\
\hline Black only & $0.29(0.16-0.51)^{\S}$ & $0.33(0.18-0.61)^{\S}$ & $0.85(0.46-1.59)$ & $1.09(0.44-2.75)$ \\
\hline American Indian/Alaska Native only & $0.39(0.21-0.75)^{\ddagger}$ & $0.47(0.22-1.00)^{\ddagger}$ & $0.39(0.21-0.73)^{\ddagger}$ & $0.34(0.13-0.89)^{\ddagger}$ \\
\hline Asian/Pacific Islander only & $0.28(0.15-0.55)^{\S}$ & $0.21(0.10-0.44)^{\S}$ & $0.89(0.44-1.81)$ & $0.45(0.15-1.32)$ \\
\hline Multiple/other race & $0.37(0.22-0.63)^{\S}$ & $0.42(0.23-0.80)^{\ddagger}$ & $1.02(0.54-1.91)$ & $1.67(0.72-3.87)$ \\
\hline \multicolumn{5}{|l|}{ Health insurance } \\
\hline No health insurance & Reference & Reference & Reference & Reference \\
\hline Private health insurance only & $1.60(0.92-2.77)$ & $1.47(0.77-2.81)$ & $1.37(0.66-2.87)$ & $1.09(0.41-2.91)$ \\
\hline Medicaid and/or Medicare only & $0.69(0.41-1.15)$ & $0.67(0.36-1.24)$ & $0.82(0.43-1.58)$ & $0.85(0.36-2.02)$ \\
\hline Multiple/Other health insurance & $0.34(0.17-0.67)^{\ddagger}$ & $0.46(0.21-1.03)$ & $0.48(0.23-1.02)$ & $0.66(0.24-1.83)$ \\
\hline \multicolumn{5}{|l|}{ Survey language } \\
\hline Spanish & Reference & Reference & Reference & Reference \\
\hline English & $19.5(2.65-144.1)^{\ddagger}$ & $7.14(0.87-58.76)$ & $1.99(0.59-6.74)$ & $2.28(0.41-12.86)$ \\
\hline \multicolumn{5}{|l|}{ Smoking status } \\
\hline Never smoked & Reference & Reference & Reference & Reference \\
\hline Former smoker & $1.12(0.76-1.63)$ & $1.03(0.67-1.60)$ & $0.92(0.58-1.45)$ & $1.27(0.66-2.44)$ \\
\hline Current smoker & $0.95(0.65-1.38)$ & $1.15(0.73-1.80)$ & $1.09(0.69-1.73)$ & $2.48(1.32-4.64)^{\ddagger}$ \\
\hline \multicolumn{5}{|l|}{$\begin{array}{l}\text { No. of doctor visits for a cough/cold } \\
\text { in past } 12 \text { months }\end{array}$} \\
\hline 0 & Reference & Reference & Reference & Reference \\
\hline 1 & $1.37(0.89-2.12)$ & $1.21(0.73-2.02)$ & $1.22(0.70-2.15)$ & $0.81(0.37-1.79)$ \\
\hline$\geq 2$ & $0.98(0.66-1.46)$ & $1.05(0.65-1.69)$ & $1.34(0.80-2.26)$ & $0.80(0.38-1.65)$ \\
\hline \multicolumn{5}{|l|}{$\begin{array}{l}\text { No. of times antibiotics given for } \\
\text { cough/cold during doctor visit }\end{array}$} \\
\hline 0 & Reference & Reference & Reference & Reference \\
\hline 1 & $0.91(0.49-1.68)$ & $1.05(0.48-2.33)$ & $0.74(0.32-1.69)$ & $0.48(0.14-1.64)$ \\
\hline$\geq 2$ & $0.48(0.24-0.95)$ & $0.52(0.21-1.29)$ & $0.82(0.33-2.01)$ & $0.71(0.21-2.45)$ \\
\hline \multicolumn{5}{|l|}{ Preferences for antibiotics } \\
\hline Prefer to take antibiotics & Reference & Reference & Reference & Reference \\
\hline Prefer not to take antibiotics & $2.88(1.66-5.03)^{\S}$ & $3.07(1.61-5.84)^{\ddagger}$ & $1.40(0.82-2.40)$ & $1.69(0.77-3.74)$ \\
\hline \multicolumn{5}{|l|}{ Knowledge of antibiotics } \\
\hline Incorrect & N/A & N/A & Reference & Reference \\
\hline Correct & - & - & $1.79(1.19-2.69)^{\ddagger}$ & $2.80(1.63-4.85)^{\S}$ \\
\hline \multicolumn{5}{|l|}{ Willingness to undergo arm blood test } \\
\hline Unwilling & Reference & Reference & Reference & Reference \\
\hline Neutral & $1.67(1.00-2.79)$ & $1.65(0.91-3.00)$ & $1.97(1.17-3.32)^{\ddagger}$ & $1.87(1.07-3.26)^{\ddagger}$ \\
\hline Willing & $1.32(0.89-1.95)$ & $1.19(0.75-1.87)$ & $97.55(42.91-221.80)^{\S}$ & $142.77(57.65-353.60)^{\S}$ \\
\hline
\end{tabular}

Contined 


\begin{tabular}{lccccc}
\hline & \multicolumn{2}{c}{ Antibiotic Knowledge } & & Willingness to Have a Fingerstick Test \\
& Crude $(\mathrm{n}=708)$ & Adjusted $^{*}(\mathrm{n}=632)$ & & Crude $(\mathrm{n}=677)$ & Adjusted $^{\dagger}(\mathrm{n}=652)$ \\
\hline $\begin{array}{l}\text { Willingness to undergo fingerstick test } \\
\text { Unwilling }\end{array}$ & Reference & Reference & & N/A & N/A \\
Neutral & $1.75(0.79-3.89)$ & $1.75(0.69-4.41)$ & & - & - \\
Willing & $2.11(1.30-3.43)^{\ddagger}$ & $1.97(1.13-3.44)^{\ddagger}$ & & - & - \\
\hline
\end{tabular}

Data are odds ratios (95\% confidence intervals).

*Adjusted for age, sex, race (American Indian/Alaska Native, white), ethnicity, preference for antibiotics, and type of health insurance (private).

${ }^{+}$Adjusted for race (American Indian/Alaska Native), smoking status (current smoker), knowledge of antibiotics, and willingness to undergo arm blood test.

${ }^{\ddagger}$ Significant at the 0.05 level.

${ }^{\$}$ Significant at the 0.001 level.

N/A, not applicable.

study from Europe in which the majority of patients noted they would happy to have a POC test when they consulted with a physician for acute cough; their major reason was to give their clinician more information to make better decisions about their treatment. ${ }^{28}$

\section{Implications for Clinicians, Policymakers, and Researchers}

While a fairly substantial body of evidence exists on the effectiveness of CRP POC tests to safely reduce antibiotic use for RTIs in primary carethis test is now recommended in several European countries-to our knowledge no trials of this test have occurred in US primary care settings. ${ }^{20}$ Currently, none of the various POC tests for CRP are approved for use in the United States. Evidence is weaker for the effectiveness of other inflammatory markers (eg, procalcitonin or white cell counts) to guide antibiotic use in adults in primary care. ${ }^{16}$ One reason for a lack of studies of these tests in the United States could be a misper-

Figure 1. Most frequent reasons cited by respondents for deciding to have a fingerstick test to help guide antibiotic use.

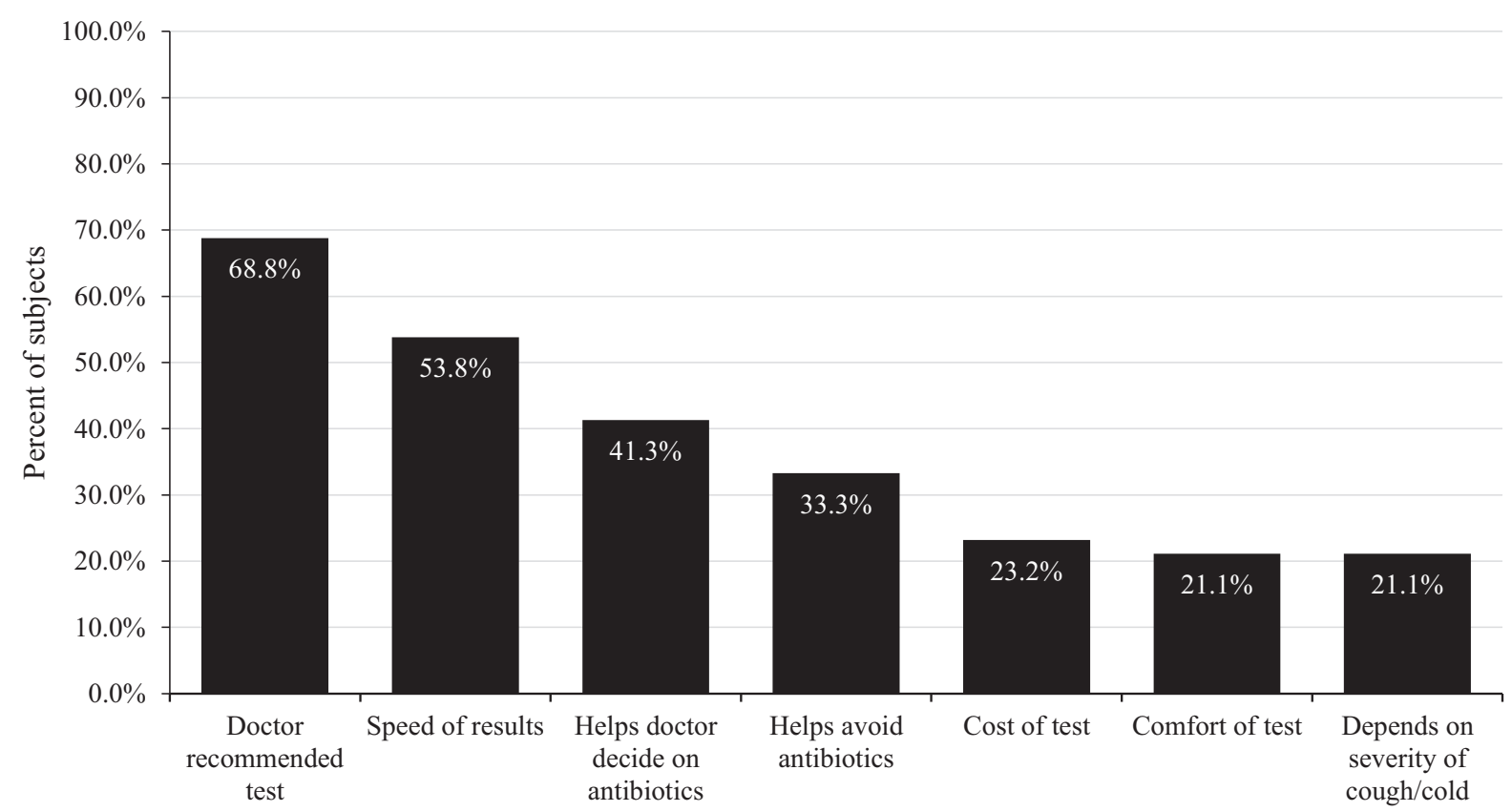

Reasons to have a fingerstick test 
ception that patients in the United States may be less willing than patients in other countries to accept such testing. Our findings suggest the opposite; the vast majority of adult patients prefer to avoid taking antibiotics for RTIs, and most would accept POC testing to guide decision making. For family physicians, our results suggest that the majority of adult patients prefer to avoid taking antibiotics for RTIs and that patients are strongly guided by what their family physician recommends in terms of the need for additional testing for RTIs. For policymakers, our findings of strong patient interest in blood tests to guide decisions around antibiotic prescribing supports the National Action Plan for Combating Antibiotic-Resistant Bacteria in primary care and ongoing initiatives such as Choosing Wisely, which have highlighted several RTIs for which antibiotics are overused. ${ }^{15,29}$ Our findings also underscore patients' need for transparency regarding the rationale behind physicians' antibiotic prescribing decisions. Specifically, the provision of clearer information to patient populations who pressure physicians to prescribe antibiotics (eg, patients without a relationship with their physician or who frequently medicalize self-limiting illnesses), as well as underserved populations and those with lower levels of education, may strengthen frontline efforts at antibiotic stewardship. ${ }^{22}$ For researchers, the results of this and other recent studies support the need for research to determine the role and effectiveness of office diagnostic tests in US primary care settings to safely reduce antibiotic use. ${ }^{22,23,30}$

The authors acknowledge the support of Dr. Rex Force and of the clinic staff and patients who participated in this study.

To see this article online, please go to: http://jabfm.org/content/ 30/5/645.full.

\section{References}

1. Schappert SM, Rechtsteiner EA. Ambulatory medical care utilization estimates for 2007. Vital Health Stat 13 2011;169:1-38.

2. Butler CC, Hood K, Verheij T, et al. Variation in antibiotic prescribing and its impact on recovery in patients with acute cough in primary care: prospective study in 13 countries. BMJ 2009;338:b2242.

3. Ebell MH, Lundgren J, Youngpairoj S. How long does a cough last? Comparing patients' expectations with data from a systematic review of the literature. Ann Fam Med 2013;11:5-13.

4. Dempsey PP, Businger AC, Whaley LE, Gagne JJ, Linder JA. Primary care clinicians' perceptions about antibiotic prescribing for acute bronchitis: a qualitative study. BMC Fam Pract 2014;15:194.

5. Wilson AA, Crane LA, Barrett PH, Gonzales R. Public beliefs and use of antibiotics for acute respiratory illness. J Gen Intern Med 1999;14:658-62.

6. Shapiro D, Hicks L, Pavia A, Hersh A. Antibiotic prescribing for adults in ambulatory care in the USA, 2007-09. J Antimicrob Chemother 2014;69:234-40.

7. Little P, Stuart B, Moore M, et al. Amoxicillin for acute lower-respiratory-tract infection in primary care when pneumonia is not suspected: a 12-country, randomised, placebo-controlled trial. Lancet Infect Dis 2013;13:123-9.

8. Smith SM, Fahey T, Smucny J, Becker LA. Antibiotics for acute bronchitis. Cochrane Database Syst Rev 2014;(3):CD000245.

9. Harris AM, Hicks LA, Qaseem A; High Value Care Task Force of the American College of Physicians and for the Centers for Disease Control and Prevention. Appropriate antibiotic use for acute respiratory tract infection in adults: advice for high-value care from the American College of Physicians and the Centers for Disease Control and Prevention. Ann Intern Med 2016;164:425-34.

10. Whaley LE, Businger AC, Dempsey PP, Linder JA. Visit complexity, diagnostic uncertainty, and antibiotic prescribing for acute cough in primary care: a retrospective study. BMC Fam Pract 2013;14:120.

11. van Vugt SF, Verheij TJ, de Jong PA, et al. Diagnosing pneumonia in patients with acute cough: clinical judgment compared to chest radiography. Eur Respir J 2013;42:1076-82.

12. Worrall G, Kettle A, Graham W, Hutchinson J. Postdated versus usual delayed antibiotic prescriptions in primary care: reduction in antibiotic use for acute respiratory infections? Can Fam Physician 2010;56:1032-6.

13. Llor C, Bjerrum L. Antimicrobial resistance: risk associated with antibiotic overuse and initiatives to reduce the problem. Ther Adv Drug Saf 2014;5: 229-41.

14. McDonagh M, Peterson K, Winthrop K, et al. Improving antibiotic prescribing for uncomplicated acute respiratory tract infections. Comparative effectiveness review no. 163. (Prepared by the Pacific Northwest Evidence-based Practice Center under Contract No. 290-2012-00014-I.) AHRQ publication no. 15(16)-EHC033-EF. Rockville, MD: Agency for Healthcare Research and Quality; 2016. Available from: www.effectivehealthcare.ahrq.gov/reports/final. cfm.

15. Office of the Press Secretary, The White House. Task Force for Combating Antibiotic-Resistant Bacteria. National action plan for combating antibiotic-resistant bacteria. Washington, DC: U.S. Government Printing Office; 2015. Available from: https://www. whitehouse.gov/sites/default/files/docs/national_ 
action_plan_for_combating_antibotic-resistant bacteria.pdf. Accessed October 29, 2016.

16. Gaynes R, Levy S. Improving outpatient antibiotic prescribing for respiratory tract infections: results of new algorithms used in European trials. Infect Control Hosp Epidemiol 2015;36:725-9.

17. Brouwer N, van Pelt J. Validation and evaluation of eight commercially available point of care CRP methods. Clin Chim Acta 2015;439:195-201.

18. van der Meer V, Neven AK, van den Broek PJ, Assendelft WJ. Diagnostic value of $\mathrm{C}$ reactive protein in infections of the lower respiratory tract: systematic review. BMJ 2005;331:26.

19. Flanders SA, Stein J, Shochat G, et al. Performance of a bedside C-reactive protein test in the diagnosis of community-acquired pneumonia in adults with acute cough. Am J Med 2004;116:529-35.

20. Huang Y, Chen R, Wu T, Wei X, Guo A. Association between point-of-care CRP testing and antibiotic prescribing in respiratory tract infections: a systematic review and meta-analysis of primary care studies. Br J Gen Pract 2013;63:e787-94.

21. Cals JW, Schot MJ, de Jong SA, Dinant GJ, Hopstaken RM. Point-of-care C-reactive protein testing and antibiotic prescribing for respiratory tract infections: a randomized controlled trial. Ann Fam Med 2010;8:124-33.

22. Hardy V, Thompson M, Keppel GA, et al. A qualitative study of primary care clinicians' views on point of care testing for C-reactive protein for acute respiratory tract infections in family medicine. BMJ Open 2017;7:e012503.

23. Howick J, Cals JW, Jones C, et al. Current and future use of point-of-care tests in primary care: an international survey in Australia, Belgium, the Neth- erlands, the UK and the USA. BMJ Open 2014;4: e005611.

24. Hardy V, Thompson M, Alto W et al. Exploring the barriers and facilitators to use of point of care tests in family medicine clinics in the United States. BMC Fam Pract 2016;17:149.

25. Cals JW, Boumans D, Lardinois RJ, et al. Public beliefs on antibiotics and respiratory tract infections: an Internet-based questionnaire study. $\mathrm{Br} \mathrm{J}$ Gen Pract 2007;57:942-7.

26. Harris P, Taylor R, Thielke R, Payne J, Gonzalez N, Conde JG. Research electronic data capture (REDCap)-a metadata-driven methodology and workflow process for providing translational research informatics support. J Biomed Inform 2009; 42:377-81.

27. Dempsey PP, Businger AC, Whaley LE, Gagne JJ, Linder JA. Primary care clinicians' perceptions about antibiotic prescribing for acute bronchitis: a qualitative study. BMC Fam Pract 2014;15:194.

28. Wood F, Brookes-Howell L, Hood K, et al. A multicountry qualitative study of clinicians' and patients' views on point of care tests for lower respiratory tract infection. Fam Pract 2011;28:661-9.

29. American Board of Internal Medicine Foundation. Choosing Wisely: promoting conversations between providers and patients. 2012. Available from: http:// www.choosingwisely.org/. Accessed November 3, 2016.

30. Minnaard MC, de Groot JA, Hopstaken RM, et al. The added value of C-reactive protein measurement in diagnosing pneumonia in primary care: a metaanalysis of individual patient data. CMAJ 2016. pii: cmaj.151163 [Epub ahead of print]. 
1. How old are you? years

2. Gender: $\square$ Male $\square$ Female

3. How would you describe your overall health?
$\square$ Excellent $\quad \square$ Moderate $\quad \square$ Poor
$\square$ Good $\quad \square$ Fair

4. Which best describes your smoking status?

$\square$ Current smoker

$\square$ Past smoker

$\square$ Non-smoker

5. What is your ethnicity?

$\square$ Hispanic/latino

$\square$ Non-hispanic/latino

6. What is your race? (check all that apply)

$\square$ American Indian/Alaska Native

$\square$ Asian

$\square$ Pacific Islander

$\square$ Black or African American

$\square$ White/Caucasian

$\square$ Other

7. What type of health insurance do you have? (check all that apply)
$\square$ None
$\square$ Medicaid
$\square$ I do not know
$\square$ Private insurance
$\square$ Medicare
$\square$ Other

8. In the last 12-months, how many times have you visited your doctor because of a cough or cold? times

9. In the last 12-months, how many times has your doctor given you an antibiotic to treat a cough or cold? times

10. Which of the following statements most applies to you? (please check ONE)

$\square$ I prefer to take antibiotics for a cough or cold, even if my doctor thinks antibiotics may not help me.

$\square$ I prefer to avoid taking antibiotics, but I will take antibiotics if my doctor thinks they will help my cough or cold.

11. I understand that antibiotics are best for treating coughs and colds that are caused by (please check ONE)

$\square$ Viruses

$\square$ Bacteria

$\square$ Viruses and bacteria

$\square$ I do not know

12. A blood test can sometimes help doctors decide if you need to take antibiotics for a cough/cold. This usually means taking blood from your arm, and waiting a day or two for the result. How willing would you be to have a test like this? (please circle ONE)

\begin{tabular}{|c|c|c|c|c|}
\hline $\begin{array}{c}1 \\
\text { Very } \\
\text { unwilling }\end{array}$ & $\begin{array}{c}2 \\
\text { Somewhat } \\
\text { unwilling }\end{array}$ & $\begin{array}{c}3 \\
\begin{array}{c}\text { Neither } \\
\text { willing or } \\
\text { unwilling }\end{array}\end{array}$ & $\begin{array}{c}4 \\
\text { Somewhat } \\
\text { willing }\end{array}$ & $\begin{array}{c}5 \\
\text { Very willing }\end{array}$ \\
\hline
\end{tabular}

13. What if your doctor could take a blood test by pricking your finger to collect a small drop of blood, and have the result within a few minutes during your visit.

How willing would you be to have a test now? (circle ONE)

\begin{tabular}{|c|c|c|c|c|}
\hline $\begin{array}{c}1 \\
\text { Very } \\
\text { unwilling }\end{array}$ & $\begin{array}{c}2 \\
\text { Somewhat } \\
\text { unwilling }\end{array}$ & $\begin{array}{c}\text { Neither willing } \\
\text { or unwilling }\end{array}$ & $\begin{array}{c}4 \\
\text { Somewhat } \\
\text { willing }\end{array}$ & $\begin{array}{c}5 \\
\text { Very willing }\end{array}$ \\
\hline
\end{tabular}

14. What would help you decide to have this new finger prick blood test?

Please check THREE boxes only for your 3 most important reasons:

$\square$ My doctor recommended the test

$\square$ Speed of results

$\square$ How much the test will cost me

$\square$ Comfort of test procedure

$\square$ If it helped me avoid taking antibiotics unnecessarily

$\square$ If it helped my doctor know if antibiotics will help my cough/cold

$\square$ It would depend how severe my cough/cold is

$\square$ Other (please describe)

\section{Thank you for completing this survey!}

Please put your completed survey in the study collection box in the waiting room

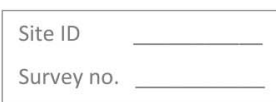

\section{Your opinions on blood tests to help doctors decide if you REALLY need antibiotics}

[NAME OF CLINIC] is involved in a research study with the University of Washington. We want to understand patient's opinions of blood tests to help doctors decide when to treat coughs and colds with antibiotics.

This brief survey will ask about your general health, antibiotic use and opinions of blood tests. The results of this survey will help us understand how to provide better care to patients in future.

- This survey should take less than 5 minutes to complete

- This survey is anonymous, meaning you will not be able to be identified from your answers.

- Taking part in this study is voluntary. It is your choice whether or not you fill out this survey.

- You do not have to answer any questions you do not want to answer.

PLEASE DO NOT FILL OUT THIS FORM IF:

You are younger than 18 years of age

You have already completed this form in the last 2 weeks

If you have questions about this research study, please contact Gina Keppel, (206) 685-0750, gakeppel@uw.edu

\section{0}

